\title{
eWOM dan Trust sebagai Prediktor terhadap Purchase Intention: Brand Image sebagai Variabel Mediasi
}

\author{
Hendro Hendro, Keni Keni
}

Universitas Tarumanagara, Jl. Tanjung Duren Utara No. 1, Jakarta Barat 11470

hendro.115160072@stu.untar.ac.id; keni@fe.untar.ac.id

Masuk tanggal : 02-05-2020, revisi tanggal : 30-07-2020, diterima untuk diterbitkan tanggal : 12-08-2020

\begin{abstract}
Purchase Intention is an evaluation stage where consumers describe the preferences between brands within a choice and allow it to be able to present an intention in making a purchase of the brand that is most in demand. Purchase Intention is very important for a brand because it can describe the impression of retention from consumers. The advantage for companies in knowing consumer retention so that companies can maintain relationships with consumers in the long term. The purpose of this research is to examine 1) $e$-WOM and trust can predict purchase intention, 2) e-WOM can predict brand image, 3) brand image can predict purchase intention, 4) brand image mediates the prediction E-WOM on purchase intention. The sampling collection used in this study is the nonprobability sampling technique. Conceptual models and analyzes related to hypotheses using convenience sampling. Data collected using a questionnaire with a total of 151 respondents. The sample of this study is consumers who have used or are currently using the brand sport shoes. The results of this study indicate that trust is a positive and significant predictor towards purchase intention. E-WOM is a positive but not significant predictor towards purchase intention. E-WOM is a positive and significant predictor towards brand image. Brand image is a positive and significant predictor of purchase intentions. Brand image can mediate positively and significantly between E-WOM towards purchase intention. This research shows that the existence of E-WOM in an era that is sophisticated as it is today is not necessarily fully able to have a positive impact on communication between companies and consumers in delivering excellence and advantages in using products that are owned by the company. This is because in increasing consumer purchase intentions for company products there are so many aspects or factors that can influence them besides E-WOM. The results of this study are expected to provide advice and input to companies in making planning and decision making going forward.
\end{abstract}

Keywords: brand image, e-WOM, purchase intention, trust

\begin{abstract}
Abstrak
Purchase Intention adalah suatu tahapan evaluasi dimana konsumen menggambarkan preferensi antara merek di dalam sebuah pilihan dan memungkinkan untuk dapat menghadirkan suatu niat dalam melakukan pembelian terhadap merek yang paling diminati. Purchase Intention sangat penting bagi suatu merek karena dapat menggambarkan kesan retensi dari konsumen. Keuntungan bagi perusahaan dalam mengetahui retensi konsumen agar perusahaan dapat menjaga hubungan dengan konsumen dalam jangkah waktu panjang. Tujuan penelitian adalah untuk menguji apakah 1) $e$-WOM dan kepercayaan dapat memprediksi niat beli. 2) $E$-WOM dapat memprediksi
\end{abstract}


citra merek. 3) citra merek dapat memprediksi niat beli. 4) citra merek memediasi prediksi $E$-WOM pada niat beli. Pengumpulan sampling yang digunakan pada penelitian ini ialah dengan teknik non-probability sampling. Model konseptual dan analisis terkait dengan hipotesis menggunakan convenience sampling. Data dikumpulkan menggunakan kuesioner dengan total 151 responden. Sampel penelitian ini adalah konsumen yang pernah atau sedang menggunakan sepatu olahraga merek tersebut. Hasil penelitian menunjukkan bahwa kepercayaan adalah prediktor positif dan signifikan terhadap niat pembelian. E-WOM adalah prediktor positif tetapi tidak signifikan terhadap niat beli. $E$ WOM adalah prediktor positif dan signifikan terhadap citra merek. Citra merek adalah prediktor positif dan signifikan dari niat beli. Citra merek dapat memediasi secara positif dan signifikan antara $E$-WOM terhadap niat beli. Penelitian ini menunjukkan bahwa adanya $E$-WOM pada jaman yang sudah canggih seperti saat ini, tidak sepenuhnya dapat memberikan dampak yang positif terhadap komunikasi antara perusahaan dengan kon sumen dalam penyampaian keunggulan dan keuntungan dalam menggunakan produk yang dimiliki oleh perusahaan. Hal ini dikarenakan dalam meningkatkan niat pembelian konsumen terhadap produk perusahaan terdapat beberapa aspek atau faktor lain yang dapat mempengaruhinya selain E-WOM.Hasil penelitian ini diharapkan dapat memberikan saran dan masukan kepada perusahaan dalam membuat perencanaan dan pengambilan keputusan kedepannya.

Kata Kunci: citra merek, $e$-WOM, kepercayaan, niat beli

\section{Pendahuluan}

Olahraga merupakan sebuah aktivitas yang tidak dapat dijauhkan dari kehidupan manusia. Saat melakukan olahraga terkadang sering terjadi yang namanya cedera seperti keseleo, otot tertarik, dan cedera lainnya (Kompasiana, 2017). Untuk mengurangi terjadinya cedera yang dialami saat berolahraga terdapat beberapa cara untuk mencegahnya seperti pilih jenis olahraga yang tepat, gunakan peralatan olahraga yang tepat, dan masih banyak lainnya (Puji, 2018). Dengan adanya permasalahan yang terjadi seperti yang disebutkan di atas, banyak perusahaan olahraga dunia yang mencoba peruntungannya untuk membuka store dan menjual berbagai macam alat olahraga. Berdasarkan pada Top Brand Award tahun 2018-2019, terdapat beberapa brand sepatu olahraga yang memiliki tingkat popularitias cukup tinggi di mata masyarakat Indonesia seperti Adidas, Nike, Ardiles, Reebok dan Diadora (Top Brand Award, 2018,2019). Hal ini memberikan dorongan bagi perusahaan untuk terus mempertahankan popularitas mereka dengan mempromosikan keunggulan-keunggulan yang dimiliki oleh masing-masing brand agar masyarakat Indonesia tetap terus melakukan pembelian kembali terhadap brand-brand tersebut. Untuk meningkatkan dan mempertahankan niat pembelian dari konsumen maka perusahaan harus dapat mempertahankan kepercayaan konsumen terhadap brand perusahaan, membentuk citra merek yang baik di dalam benak konsumen, menjaga kualitas produk dan meningkatkan pelayanan terhadap konsumen.

Purchase intention dapat didefinisikan sebagai suatu bentuk dari perilaku seorang konsumen yang memiliki keinginan untuk memilih atau membeli suatu produk berdasarkan pada pengalaman, penggunaan, dan keinginannya terhadap suatu produk (Kotler \& Keller, 2016). Berdasarkan penelitian terdahulu, ada 
Hendro Hendro, Keni Keni: eWOM dan Trust sebagai Prediktor terhadap Purchase Intention: Brand Image sebagai Variabel Mediasi

beberapa faktor yang dapat mempengaruhi purchase intention. Penelitian yang dilakukan oleh Bianchi dan Andrews (2012) menunjukkan bahwa attitude dan trust memiliki pengaruh positif terhadap purchase intention. Pada penelitian Liu et al. (2017) menyatakan bahwa website appeal partially dan trust dapat memprediksi purchase intention secara positif. Hasil penelitian Lee et al. (2011) menunjukkan bahwa semakin besar credibility dan trust yang dirasakan oleh online consumer review maka akan semakin tinggi purchase intention. Lebih lanjut, Jalilvand dan Samiei (2012) menekankan bahwa brand image dan purchase intention dapat diprediksi secara positif oleh variabel E-WOM, selanjutnya purchase intention dapat diprediksi secara positif oleh variabel brand image.

Penelitian ini memiliki keterkaitan dengan the commitment-trust theory yang dikemukakan oleh Morgan dan Hunt (2016). Pada teori ini menjelaskan adanya hubungan antara kepercayaan dengan komitmen yang menjelaskan keberhasilan dalam relationship marketing. The commitment-trust theory ini menggambarkan adanya label dalam model variabel mediasi dari relationship marketing yang memiliki fokus terhadap pihak yang mengalami pertukaran relasi (antara brand dengan konsumen) serta hubungan komitmen dan kepercayaan yang didapatkan dari pihak tersebut. Keterkaitan teori yang dijelaskan di atas terhadap variabel penelitian ini adalah memiliki rasa kepercayaan pada suatu merek maka akan memunculkan rasa kesetiaan dan keyakinan bagi konsumen dan meningkatkan keinginan konsumen dalam membeli produk perusahaan. Konsumen yang merasakan nama merek menjadi menguntungkan serta memiliki reputasi, maka konsumen akan cenderung lebih percaya pada merek tersebut (Japutra, Keni \& Nguyen, 2015). Selain memiliki rasa kepercayaan terhadap suatu brand perusahaan, akan membuat citra merek perusahaan akan baik di mata konsumen. Pada saat konsumen sudah memiliki kepercayaan dan mengetahui tentang citra merek perusahaan yang baik, maka hal ini akan membuat konsumen untuk semakin tidak ragu dalam menyebarkan informasi yang baik mengenai brand perusahaan tersebut. Konsumen pasti yakin dalam melakukan pembelian terhadap produk perusahaan ketika konsumen percaya terhadap brand perusahaan dan perusahaan memiliki citra merek yang baik di mata konsumen serta didukung dengan informasi yang baik tentang brand perusahaan tersebut. Hubungan yang digambarkan lewat kepercayaan dan informasi yang bernilai tinggi sehingga kedua belah pihak akan memiliki keinginan untuk saling berkomitmen terhadap hubungan.

Penelitian dilakukan untuk (1) menganalisis pengaruh $e$-WOM, Trust, dan Brand image sebagai prediktor positif terhadap variabel Purchase intention, (2) menganalisis pengaruh e-WOM, Trust, dan Brand image terhadap Brand image, dan (3) menganalisis pengaruh $e$-WOM terhadap Purchase intention. Diharapkan dengan dilakukannya penelitian ini dapat memberikan manfaat berupa informasi terkait dengan variabel-variabel yang berpengaruh secara signifikan terhadap variabel Purchase intention. 


\section{Purchase intention}

Menurut Kotler dan Keller (2016: 198) menjelaskan bahwa purchase intention merupakan "a form of behavior from consumers who wish to buy or choose a product that is based on experience, use and desires on a product". Lebih lanjut, Garg dan Joshi (2018: 686) "Purchase intention refers to the mental stage in the decision-making process where the consumer has developed an actual willingness to act toward an object or brand."

Berdasarkan pada pengertian di atas, maka peneliti menyimpulkan bahwa purchase intention merupakan bentuk dari perilaku seorang konsumen yang bersedia melakukan pembelian terhadap suatu produk yang didasari dengan pengalaman, keinginan dan penggunaan terhadap produk.

\section{Trust}

Menurut Soares et al. (2012: 48) menjelaskan bahwa trust ialah: "a belief or expectation that the trusted party is reliable and dependable". Lebih lanjut, Delgado-Ballester \& Munuera-Alemán (2005: 1242) berpendapat bahwa trust adalah: ".. a feeling of security held by the consumer that the brand will meet hihe/sher consumption expectations..brand reliability and brand intentions towards the individual."

Berdasarkan pada pengertian di atas maka peneliti dapat menyimpulkan bahwa trust adalah keyakinan atau harapan yang dimiliki oleh individu maupun kelompok individu dalam melakukan transaksi dengan tujuan merek tersebut dapat memenuhi niat dan harapan konsumsi.

\section{Brand image}

Menurut Farzin dan Fattahi (2018: 165) mengemukakan bahwa brand image adalah: "BI encompasses attributes and benefits associated with a brand that make the brand distinctive and distinguish the firm's offer from that of its competitors." Lebih lanjut, Syed Alwi dan Kitchen (2014: 2325) menjelaskan bahwa brand image adalah: "a subjective, perceptual phenomenon that is formed through rational and emotional interpretation."

Berdasarkan pada pengertian di atas maka peneliti dapat menyimpulkan bahwa brand image merupakan persepsi dalam memori konsumen yang terbentuk melalui tingkat rasional dan interpretasi emosional terhadap merek dan penawaran yang diberikan oleh perusahaan.

\section{$e-W O M$}

Menurut Abubakar et al. (2016: 692) eWOM adalah: "any positive or negative statement made by present or previous customers about a product, service or company, which is made available to large audiences via the internet." Lebih lanjut, Prasad et al. (2017: 136) menjelaskan bahwa eWOM sebagai: "Consumers gather information about company or product using internet, and hence eWOM has emerged as important tool."

Berdasarkan pada pengertian di atas, maka dapat disimpulkan bahwa eWOM sebagai komunikasi pribadi bagi seorang konsumen dalam mengumpulkan dan mendapatkan informasi mengenai produk ataupun jasa yang dijual oleh 
Hendro Hendro, Keni Keni: eWOM dan Trust sebagai Prediktor terhadap Purchase Intention: Brand Image sebagai Variabel Mediasi

perusahaan yang memengaruhi terhadap keputusan pembelian yang akan dilakukan oleh konsumen.

\section{Kaitan antara $E$-WOM dan Purchase intention}

Abubakar et al. (2016) menjelaskan bahwa eWOM memiliki keterkaitan secara positif terhadap purchase intention. Dalam hal ini eWOM memainkan suatu peran yang penting dalam mempengaruhi sikap konsumen serta niat pembelian. Media sosial dikatakan sebagai pendorong bagi penggunanya untuk menyebarkan pesan komunikasi secara online (Kusumasari \& Arifianto, 2019). Pada jaman sekarang, eWOM dikatakan sebagai suatu iklan gratis yang memiliki efektifitas yang baik karena pemasaran yang bersifat tradisional sudah mulai kehilangan efektifitasnya. Farzin dan Fattahi (2018) mengatakan bahwa pada perubahan dari WOM menjadi eWOM, telah menjadi faktor yang penting dalam mempengaruhi proses pembentukan perilaku pembelian konsumen. Karena perilaku konsumen eWOM sudah menjadi salah satu faktor penting dalam membentuk perilaku konsumen dalam pengambilan keputusan pembelian bagi konsumen. Terdapat pengaruh positif secara langsung maupun tidak langsung antara e-WOM terhadap purchase intention. Selain itu, penelitian yang dilakukan Kudeshia dan Kumar (2017) menjelaskan bahwa e-WOM terjadi ketika konsumen memberikan rekomendasi terkait dengan produk perusahaan melalui situs jaringan yang berbeda. Pada penelitian ini menunjukkan adanya pengaruh positif yang kuat antara e-WOM terhadap purchase intention. Berdasarkan uraian di atas, maka hipotesis penelitian $\left(\mathrm{H}_{1 \mathrm{a}}\right)$ sebagai berikut:

$\mathrm{H}_{1 \mathrm{a}}$ : $\quad$ E-WOM dapat memprediksi secara positif purchase intention.

\section{Kaitan antara Trust dan Purchase intention}

Bianchi dan Andrews (2012) menjelaskan bahwa dengan adanya faktor kepercayaan baik dari sisi orang ketiga maupun lingkungan budaya kepercayaan mempunyai pengaruh yang positif kuat terhadap purchase intention. Rasa percaya itu sendiri timbul karena adanya nilai sosialisasi individu yang berada di dalam suatu negara asalnya sehingga konsumen bertindak sebagai seseorang individu dengan berdasarkan pada nilai budaya negara asal yang memengaruhi niat pembelian konsumen dalam melakukan suatu keputusan pembelian. Pada penelitian Liu et al. (2017) dikemukakan bahwa terdapat pengaruh positif yang kuat antara trust terhadap purchase intention. Kepercayaan memberikan pengaruh terhadap daya tarik suatu produk dan situs web terhadap niat pembelian konsumen. Dapat dikatakan bahwa dengan adanya nilai kepercayaan terhadap suatu produk perusahaan dapat memengaruhi niat pembelian bagi seorang konsumen. Perusahaan perlu meningkatkan nilai kepercayaan konsumen agar produk perusahaan dapat memiliki daya tarik yang kuat bagi konsumen. Kepercayaan yang dimiliki oleh konsumen dapat dijadikan sebagai suatu kontributor penting untuk niat pembelian konsumen (Kim \& Park, 2013).

Lee et al. (2011) dalam penelitiannya mengatakan bahwa terdapat pengaruh positif antara trust dengan purchase intention. Trust merupakan keyakinan atau harapan yang dimiliki oleh individu maupun kelompok individu dalam melakukan transaksi dengan tujuan merek dapat memenuhi niat dan 
harapan konsumsi. Jika konsumen sudah memiliki tingkat kepercayaan yang tinggi terhadap produk perusahaan maka tidak perlu diragukan lagi oleh perusahaan terhadap niat pembelian konsumen. Berdasarkan uraian di atas, maka hipotesis penelitian $\left(\mathrm{H}_{1 \mathrm{~b}}\right)$ sebagai berikut:

$\mathrm{H}_{1 \mathrm{~b}}$ : Trust dapat memprediksi secara positif purchase intention

\section{Kaitan antara $E$-WOM dan Brand image}

Menurut Farzin dan Fattahi (2018) mengatakan bahwa terdapat pengaruh positif antara eWOM terhadap brand image. Brand image dijadikan sebagai suatu atribut yang dapat memberikan manfaat dari perusahaan kepada konsumen yang membedakan penawaran antara perusahaan dengan para pesaing lainnya. Konsumen akan memperhatikan mengenai eWOM. Semakin banyak eWOM yang bersifat positif maka akan memberikan peluang yang besar bagi perusahaan dalam membangun citra merek yang bersifat positif juga di mata konsumen. Pada akhirnya gambaran positif ini akan membangun nilai kepercayaan terhadap citra merek perusahaan. Dalam penelitian yang dilakukan oleh Abubakar et al. (2016) dapat ditemukan bahwa adanya pengaruh positif antara e-WOM dengan brand image. Dengan adanya hypermedia yang semakin canggih pada jaman ini maka akan memberikan peluang dalam bidang komunikasi. E-WOM sendiri akan dapat berkembang dengan baik dan juga informasi yang didapatkan akan lebih mudah. Dengan adanya komunikasi e-WOM yang mudah didapatkan, akan memberikan peluang yang besar bagi perusahaan dalam membangun citra mereknya yang dirasakan oleh konsumennya. Jalilvand dan Samiei (2012) mengatakan bahwa hadirnya e-WOM akan memberikan peningkatan terhadap citra merek perusahaan di mata konsumen sehingga dengan adanya hal ini akan memberikan dampak pada pengurangan biaya promosi yang dilakukan oleh perusahaan. E-WOM telah menjadi sebuah elemen permanen dalam bauran pemasaran dengan memberikan kontribusi besar pada citra merek perusahaan. Berdasarkan uraian di atas, maka hipotesis penelitian $\left(\mathrm{H}_{2}\right)$ sebagai berikut:

$\mathrm{H}_{2}$ : $\quad$ E-WOM dapat memprediksi secara positif brand image

\section{Kaitan antara Brand image dan Purchase intention}

Menurut $\mathrm{Yu}$ et al. (2018) terdapat pengaruh positif antara brand image terhadap purchase intention. Dalam memiliki citra merek yang baik, perusahaan harus dapat memaksimalkan peluang yang ada. Hal ini dapat membuat konsumen semakin yakin dengan produk dan layanan yang diberikan oleh perusahaan. Pada penelitian yang dilakukan oleh Farzin dan Fattahi (2018) ditemukannya pengaruh positif antara brand image terhadap purchase intention. Dalam proses pembentukan brand image yang baik di dalam benak konsumen maka akan memengaruhi juga terhadap keputusan pembelian bagi konsumen. Lebih lanjut, Jalilvand dan Samiei (2012) mengatakan bahwa brand image mempengaruhi purchase intention. Dengan meningkatkannya citra merek dalam suatu perusahaan maka akan meningkatnya juga niat pembelian konsumen terhadap produk perusahaan. Berdasarkan uraian di atas, maka hipotesis penelitian $\left(\mathrm{H}_{3}\right)$ sebagai berikut:

$\mathrm{H}_{3}$ : $\quad$ Brand image dapat memrediksi secara positif purchase intention 
Hendro Hendro, Keni Keni: eWOM dan Trust sebagai Prediktor terhadap Purchase Intention: Brand Image sebagai Variabel Mediasi

\section{Kaitan antara E-WOM dan Purchase intention yang dimediasi Brand image}

Menurut Farzin dan Fattahi (2018) menjelaskan bahwa sebelum konsumen melakukan purchase intention, konsumen akan melakukan pencarian informasi dalam meningkatkan kepercayaan terhadap suatu produk. Pada saat ini peran brand image penting karena dapat membedakan produk perusahaan dengan pesaingnya. Lebih Lanjut Lin et al. (2013) mengatakan bahwa sudah dilakukan suatu pengujian dimana pada pengujian yang menyatakan adanya pengaruh positive bagi brand image dalam memediasi e-WOM dengan purchase intention. Pada penjelasan di atas dapat disimpulkan bahwa brand image dapat memediasi secara positif antara e-WOM dengan purchase intention. Berdasarkan uraian di atas, maka hipotesis penelitian $\left(\mathrm{H}_{4}\right)$ sebagai berikut:

$\mathrm{H}_{4}$ : Brand image dapat memediasi prediksi secara positif E-WOM terhadap purchase intention

Berdasarkan pada uraian kaitan antar variabel di atas, maka model penelitian dalam penelitian ini digambarkan sebagai berikut:

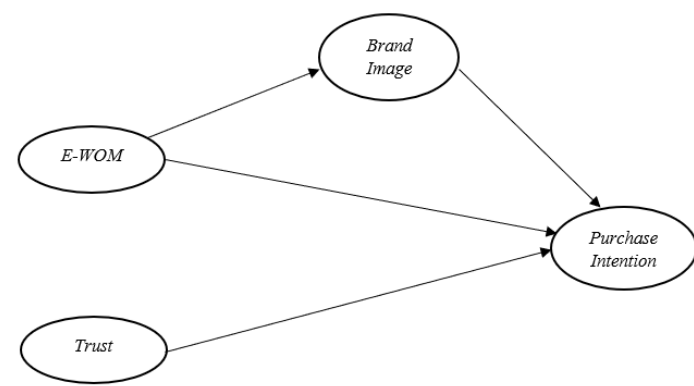

Gambar 1: Model penelitian (Sumber: hasil pengolahan data oleh peneliti)

\section{Metode Penelitian}

Penelitian didesain sebagai penelitian deskriptif dengan pendekatan cross sectional. Sampel penelitian ini adalah konsumen yang pernah atau sedang menggunakan sepatu olahraga merek tersebut. Pengumpulan sampling yang digunakan pada penelitian ini ialah dengan teknik non-probability sampling "convenience." Jumlah responden yang diambil oleh peneliti sebanyak 151 responden. Dari jumlah 151 responden yang digunakan dalam penelitian ini, mayoritas responden berjenis kelamin pria (59\%), berusia di antara 17-24 tahun (89\%), memiliki pendidik terakhir SMA (67\%), dan memiliki pekerjaan sebagai seorang pelajar $(83 \%)$. Sementara, objek penelitian terdiri dari eWOM, trust, brand image dan purchase intention. Indikator pengukuran variabel penelitian ini disajikan pada Tabel 1 berikut ini. 
Tabel 1. Indikator Pengukuran Variabel

\begin{tabular}{ccc}
\hline Variabel & Item & Sumber \\
\hline Purchase Intention & 5 item & Abubakar et al. (2016); Bigné dan Currás (2008); Chen \\
et al. (2015).
\end{tabular}

Pada penelitian ini semua variabel yang digunakan diukur dengan menggunakan skala Likert yang memiliki 5 poin, dimana angka 1 menyatakan "Sangat Tidak Setuju" dan terakhir angka 5 menyatakan "Sangat Setuju". Pada tahap analisis validitas dan reliabilitas, dari total 20 item tersisa 17 item yang digunakan dalam mengukur variabel purchase intention, trust, brand image, dan $E$-WOM dikarenakan terdapat beberapa item yang memiliki nilai loading factor dibawah $0,4(<0,4)$ sehingga indikator tersebut dihapus oleh peneliti dari model penelitian (Henseler et al., 2009). Dari total 21 items yang digunakan, semuanya memiliki nilai Loading factors diatas $0,7(>0,7)$ dan memiliki nilai AVE diatas 0,5 $(>0,5)$ sehingga dapat disimpulkan bahwa telat memenuhi syarat validitas konvergen dan validitas diskriminan Fornell-Larcker serta Cross Loadings. Terakhir, pada pengujian reliabilitas menyatakan bahwa semua variabel dalam penelitian ini memiliki nilai Composite Reliabilty dan Cronbach's Alpha di atas $0,6(>0,6)$. Berarti, semua variabel yang digunakan dalam penelitian tergolong reliabel (Malhotra, 2020).

\section{Hasil Penemuan dan Diskusi}

Pada penelitian ini dilakukan juga pengujian path coefficient yang memiliki tujuan agar dapat mengetahui arah serta apakah hubungan variabel dependen dengan variabel independen dinyatakan kuat atau lemah. Di bawah ini merupakan hasil pengujian bootsraping yang ditampilkan dalam bentuk tabel.

Tabel 2. Hasil Analisis Path Coefficient

\begin{tabular}{ccccc}
\hline Hipotesis & Variabel & $\begin{array}{c}\text { Path } \\
\text { Coefficient }\end{array}$ & t-statistics & P-Values \\
\hline $\mathrm{H}_{\mathrm{a}}$ & $E$-WOM $»$ Purchase intention & 0,014 & 0,270 & 0,787 \\
\hline $\mathrm{H}_{\mathrm{bb}}$ & Trust $\gg$ Purchase intention & 0,673 & 8,875 & 0,000 \\
\hline $\mathrm{H}_{2}$ & E-WOM $\gg$ Brand image & 0,404 & 5,033 & 0,000 \\
\hline $\mathrm{H}_{3}$ & $\begin{array}{c}\text { Brand image } » \text { Purchase } \\
\text { intention }\end{array}$ & 0,182 & 2,470 & 0,014 \\
\hline $\mathrm{H}_{4}$ & $\begin{array}{c}\text { E-WOM } » \text { Brand image } \\
\text { Purchase intention }\end{array}$ & 0,074 & 2,017 & 0,044 \\
\hline
\end{tabular}

Pada hasil pengujian path coefficient yang disajikan di Tabel 2, maka dapat disimpulkan bahwa trust adalah variabel yang memiliki nilai koefisien terbesar dan memiliki arah positif dalam memprediksi purchase intention dibanding dengan variabel-variabel lain yaitu sebesar 0,673. Selanjutnya, brand 
Hendro Hendro, Keni Keni: eWOM dan Trust sebagai Prediktor terhadap Purchase Intention: Brand Image sebagai Variabel Mediasi

image yang memiliki nilai koefisien terbesar kedua dan memiliki arah positif dalam memrediksi purchase intention yaitu sebesar 0,182 dan terakhir variabel eWOM yang hanya memiliki 0,014 , variabel ini memiliki nilai koefisien terkecil dan memiliki arah positif dalam memrediksi purchase intention di antara variabel lainnya dalam penelitian ini. Dari semua variabel yang signifikan dalam memprediksi variabel purchase intention, terkecuali variabel $e$-WOM.

Berdasarkan pada hasil pengujian hipotesis $\left(\mathrm{H}_{1 \mathrm{a}}\right)$, menunjukkan bahwa hubungan antara variabel $e$-WOM terhadap niat pembelian tidak signifikan. Hal ini berbeda dengan penelitian yang dilakukan oleh Abubakar et al. (2016), Farzin dan Fattahi (2018) dan Kudeshia dan Kumar (2017) menjelaskan bahwa terdapat pengaruh positif yang kuat antara E-WOM terhadap purchase intention. E-WOM terjadi ketika konsumen memberikan rekomendasi terkait dengan produk perusahaan melalui situs jaringan yang berbeda. Perusahaan yang memiliki citra merek yang kuat dan terkenal di mata konsumen dapat meningkatkan niat pembelian konsumen tanpa memanfaatkan eWOM karena konsumen sudah mengetahui dan percaya akan merek tersebut.

Selanjutnya, pada hasil pengujian hipotesis $\left(\mathrm{H}_{1 b}\right)$, menunjukkan bahwa variabel trust dapat memprediksi variabel purchase intention secara positif. Hasil penelitian ini sama dengan penelitian terdahulu yang dilakukan oleh Bianchi dan Andrews (2012), Liu et al. (2017), dan Lee et al. (2011) dimana dengan adanya faktor trust yang dihadirkan baik dari sisi orang ketiga maupun lingkungan budaya kepercayaan akan mempunyai pengaruh yang positif terhadap purchase intention. Perusahaan perlu meningkatkan nilai kepercayaan yang dimiliki oleh konsumen karena dapat menjadi suatu kontributor penting bagi konsumen dalam memutuskan niat pembelian terhadap brand.

Hasil pengujian hipotesis $\left(\mathrm{H}_{2}\right)$, menunjukkan bahwa $e$-WOM dapat memrediksi brand image secara positif. Hasil penelitian ini sama dengan penelitian terdahulu yang dilakukan oleh Farzin dan Fattahi (2018), Abubakar et al. (2016) dan Jalilvand dan Samiei (2012) dimana Farzin dan Fattahi (2018) mengatakan bahwa brand image dapat dijadikan sebagai suatu atribut yang dapat memberikan manfaat dari perusahaan kepada konsumen yang membedakan penawaran antara perusahaan dengan para pesaing lainnya. Pada jaman saat ini, dengan adanya komunikasi eWOM yang mudah didapatkan oleh konsumen akan dapat memberikan peluang yang besar bagi brand dalam membangun citra merek yang dirasakan oleh konsumen (Abubakar et al., 2016).

Lebih lanjut, hasil pengujian terhadap hipotesis $\left(\mathrm{H}_{3}\right)$, menunjukkan bahwa brand image dapat memrediksi purchase intention secara positif. Hal ini sejalan dengan penelitian yang dilakukan oleh Yu et al. (2018), terdapat pengaruh positif antara brand image terhadap purchase intention. Hal ini juga diperkuat oleh penelitian Farzin dan Fattahi (2018) yang menemukan bahwa brand image dapat memrediksi purchase intention secara positif. Dalam proses pembentukan brand image yang baik di benak konsumen maka akan memengaruhi terhadap purchase intention bagi konsumen. Jalilvand dan Samiei (2012) mengatakan bahwa brand image memengaruhi purchase intention, dengan meningkatnya citra merek perusahaan akan berdampak positif pada niat pembelian konsumen terhadap produk perusahaan. Memiliki citra merek yang baik di mata konsumen maka 
dapat membuat konsumen semakin yakin terhadap produk dan layanan yang diberikan oleh perusahaan sehingga akan meningkatkan niat pembelian konsumen terhadap produk perusahaan.

Terakhir, pada hasil pengujian hipotesis $\mathrm{H}_{4}$, menunjukkan brand image memediasi prediksi $e$-WOM terhadap purchase intention secara positif. Hal ini sama dengan penelitian yang dilakukan oleh Farzin dan Fattahi (2018) yang menjelaskan bahwa sebelum konsumen melakukan purchase intention, konsumen akan melakukan pencarian informasi dalam meningkatkan kepercayaan terhadap suatu produk. Lin et al. (2013) mengatakan bahwa telah dilakukannya suatu pengujian yang menyatakan adanya pengaruh positif bagi brand image ketika memediasi $e$-WOM dengan purchase intention. Perusahaan menginginkan adanya peningkatan niat pembelian konsumen terhadap produk perusahaan, dalam hal ini perusahaan harus memastikan bahwa citra merek perusahaan bersifat baik di mata konsumen, dengan adanya citra merek yang baik maka informasi yang ada mengenai perusahaan tersebut juga akan bersifat positif.

\section{Simpulan}

Kesimpulan yang dapat diambil pada hasil yang dilakukan pada penelitian ini adalah $e$-WOM dapat memrediksi secara positif purchase intention namun tidak signifikan dan trust dapat memrediksi secara positif purchase intention. Lebih lanjut, $e$-WOM dapat memrediksi secara positif brand image dan brand image dapat memrediksi secara positif purchase intention. Terakhir, brand image dapat memediasi secara positif prediksi $e$-WOM terhadap purchase intention.

Perusahaan disarankan agar terus mempertahankan kepercayaan yang dimiliki konsumen terhadap brand perusahaan. Jika perusahaan dapat memberikan kualitas yang baik serta memenuhi apa yang diharapkan oleh konsumen terhadap produk perusahaan, maka hal ini dapat mempertahankan serta meningkatkan kepercayaan konsumen dan ke depannya akan meningkatkan niat pembelian konsumen terhadap produk perusahaan tersebut. Perusahaan diharapkan dapat menjaga citra merek baik yang telah dimiliki perusahaan di mata konsumen.

Untuk penelitian selanjutnya, disarankan agar dapat menambah jangkauan populasi dan wilayah yang dicakupi sehingga penelitian yang dilakukan dapat memberikan hasil yang maksimal serta akurat dalam mengukur niat pembelian konsumen terhadap produk perusahaan tersebut. Disarankan juga agar dapat menambah dan memperluas variabel-variabel yang belum digunakan dalam penelitian ini dimana variabel-variabel tersebut diharapkan dapat mengukur secara lebih akurat dan memberikan kontribusi yang lebih besar dalam memprediksi niat pembelian sepatu olahraga di Jakarta. 
Hendro Hendro, Keni Keni: eWOM dan Trust sebagai Prediktor terhadap Purchase Intention: Brand Image sebagai Variabel Mediasi

\section{Ucapan Terima Kasih}

Peneliti mengucapkan terima kasih kepada Ketua Lembaga Penelitian dan Pengabadian kepada Masyarakat (LPPM) Universitas Tarumanagara yang telah mendanai hibah penelitian tugas akhir ini. Disamping itu, ucapan terima kasih kepada Dekan Fakultas Ekonomi dan Bisnis, Ketua Jurusan Manajemen, Ketua Program Studi Sarjana Manajemen Universitas Tarumanagara, tim editorial Jurnal Komuninasi, seluruh responden dan seluruh pihak yang sudah membantu, mendukung, dan berpartisipasi dalam pelaksanaan penelitian ini.

\section{Daftar Pustaka}

Abubakar, A. M., Ilkan, M., \& Sahin, P. (2016). eWOM, eReferral and gender in the virtual community. Marketing Intelligence and Planning, 34(5), 692710. https://doi.org/10.1108/MIP-05-2015-0090

Bianchi, C., \& Andrews, L. (2012). Risk, trust, and consumer online purchasing behaviour: A Chilean perspective. International Marketing Review, 29(3), 253-275. https://doi.org/10.1108/02651331211229750

Delgado-Ballester, E., \& Munuera-Alemán, J. L. (2005). Does brand trust matter to brand equity? Journal of Product and Brand Management, 14(3), 187196. https://doi.org/10.1108/10610420510601058

Farzin, M., \& Fattahi, M. (2018). eWOM through social networking sites and impact on purchase intention and brand image in Iran. Journal of Advances in Management Research, 15(2), 161-183. https://doi.org/10.1108/JAMR-05-2017-0062

Garg, P., \& Joshi, R. (2018). Purchase intention of "Halal" brands in India: the mediating effect of attitude. Journal of Islamic Marketing, 9(3), 683-694. https://doi.org/10.1108/JIMA-11-2017-0125

Henseler, J., Ringle, C. M., \& Sinkovics, R. R. (2009). The use of partial least squares path modeling in international marketing. In Advances in International Marketing (Vol. 20). https://doi.org/10.1108/S14747979(2009)0000020014

Jalilvand, M. R., \& Samiei, N. (2012). The effect of electronic word of mouth on brand image and purchase intention: An empirical study in the automobile industry in Iran. Marketing Intelligence and Planning, 30(4), 460-476. https://doi.org/10.1108/02634501211231946

Japutra, A., Keni, K., \& Nguyen, B. (2015). The impact of brand logo identification and brand logo benefit on Indonesian consumers' relationship quality. Asia-Pacific Journal of Business Administration, 7(3), 237-252. https://doi.org/10.1108/APJBA-10-2014-0124

Kim, S., \& Park, H. (2013). Effects of various characteristics of social commerce (s-commerce) on consumers' trust and trust performance. International Journal of Information Management, 33(2), 318-332. https://doi.org/10.1016/j.ijinfomgt.2012.11.006 
Kompasiana. (2017). Tips untuk Menghindari Cedera Saat Berolahraga, Olahraga Aman untuk Badan Sehat! Www.Kompasiana.Com. https://www.kompasiana.com/paniwidi9/59c6196f78b685086c44fd32/tips -untuk-menghindari-cedera-saat-berolahraga-olahraga-aman-untuk-badansehat?page $=1$

Kotler, P., \& Keller, L. K. (2016). Marketing Management. In Marketing Management (15th editi). Pearson Pretice Hall. https://doi.org/10.4324/9780203862261

Kudeshia, C., \& Kumar, A. (2017). Social eWOM: does it affect the brand attitude and purchase intention of brands? Management Research Review, 40(3), 310-330. https://doi.org/10.1108/MRR-07-2015-0161

Kusumasari, D., \& Arifianto, S. (2019). Makna Teks Ujaran Kebencian Pada Media Sosial | Kusumasari | Jurnal Komunikasi. Jurnal Komunikasi, 12(1), $1-15$. https://journal.untar.ac.id/index.php/komunikasi/article/view/4045/4661

Lee, J., Park, D. H., \& Han, I. (2011). The different effects of online consumer reviews on consumers' purchase intentions depending on trust in online shopping malls: An advertising perspective. Internet Research, 21(2), 187-206. https://doi.org/10.1108/10662241111123766

Lin, C., Wu, Y.-S., \& Chen, J.-C. V. (2013). Electronic Word-of-Mouth: The Moderating Roles of Product Involvement and Brand Image. Proceedings of 2013 International Conference on Technology Innovation and Industrial Management, 29-47.

Liu, F., Xiao, B., Lim, E. T. K., \& Tan, C. W. (2017). The art of appeal in electronic commerce: Understanding the impact of product and website quality on online purchases. Internet Research, 27(4), 752-771. https://doi.org/10.1108/IntR-09-2016-0280

Malhotra. (2020). Marketing Research: Applied Insight.

Morgan, R. M., \& Hunt, S. D. (2016). The Commitment-Trust Theory of Relationship Marketing Authors ( $s$ ): Robert M. Morgan and Shelby D. Hunt Published by: American Marketing Association Stable URL: http://www.jstor.org/stable/1252308 REFERENCES Linked references are available on JSTOR $f$. 58(3), 20-38.

Prasad, S., Gupta, I. C., \& Totala, N. K. (2017). Social media usage, electronic word of mouth and purchase-decision involvement. Asia-Pacific Journal of Business Administration, 9(2), 134-145. https://doi.org/10.1108/APJBA-06-2016-0063

Puji, A. (2018). 7 Tips Jitu Mencegah Cedera Saat Berolahraga. Www.Hellosehat.Com. https://hellosehat.com/hidupsehat/kebugaran/mencegah-cedera-saat-olahraga/

Soares, A. M., Pinho, J. C., \& Nobre, H. (2012). From Social to Marketing Interactions: The Role of Social Networks. Journal of Transnational Management, $17(1)$, 45-62. https://doi.org/10.1080/15475778.2012.650085 
Hendro Hendro, Keni Keni: eWOM dan Trust sebagai Prediktor terhadap Purchase Intention: Brand Image sebagai Variabel Mediasi

Syed Alwi, S. F., \& Kitchen, P. J. (2014). Projecting corporate brand image and behavioral response in business schools: Cognitive or affective brand attributes? Journal of Business Research, 67(11), 2324-2336. https://doi.org/10.1016/j.jbusres.2014.06.020

TopBrandAward. (2018). Top Brand Sepatu Olahraga. Topbrand-Award.Com. https://www.topbrand-award.com/top-brand-index/?tbi_find=adidas

TopBrandAward. (2019). Top Brand Sepatu Olahraga. Topbrand-Award.Com. https://www.topbrand-award.com/top-brand-index/?tbi_find=adidas

Yu, M., Liu, F., Lee, J., \& Soutar, G. (2018). The influence of negative publicity on brand equity: attribution, image, attitude and purchase intention. Journal of Product and Brand Management, 27(4), 440-451. https://doi.org/10.1108/JPBM-01-2017-1396 